\title{
Preparation and characterization of zinc and cobalt (II, III) oxides mixture and direct red 23 diazo dye heterogeneous photocatalysis
}

\author{
GIOVANNI BÓRO PASCHOAL ${ }^{1}$, MARCELO RODRIGUES DA SILVA ${ }^{2}$ and \\ KEIKO TAKASHIMA ${ }^{1, *}$ \\ ${ }^{1}$ Laboratório de Processos de Oxidação Avançados, Departamento de Química, Caixa Postal 10011, \\ 86057-970 Londrina, Paraná, Brazil \\ ${ }^{2}$ Universidade Estadual Júlio Mesquita, Colégio Técnico Industrial, Av. Nações Unidas 58-50, 17033-260, Bauru, São \\ Paulo, Brazil
}

MS received 1 September 2014; accepted 3 February 2015

\begin{abstract}
The decolourization of the direct red 23 diazo dye, commonly used in textile industries, was investigated through the heterogeneous photocatalysis mediated by zinc oxide, $n$-type semiconductor combined with p-type cobalt oxide at $30^{\circ} \mathrm{C}$. The mixture of $n$ - and p-type semiconductors may form a p-n junction, which can decrease the band gap energy and thus increase the photocatalytic activity. This work reports the preparation and characterization of cobalt oxide and oxide mixtures of $\mathrm{Zn}$ and $\mathrm{Co}$ in 1, 3 and $5 \%$ proportions, respectively, as well as their photocatalytic activity, measured by direct red 23 diazo dye decolourization rate constants. These oxides were characterized through the $\mathrm{X}$-ray diffraction, scanning electron microscope, energy-dispersive X-ray spectroscopy, X-ray fluorescence spectroscopy and diffuse reflectance spectrophotometry. The suspension, formed from direct red 23 diazo dye solution and oxide mixtures, was kept in the dark for $1 \mathrm{~h}$ at $30^{\circ} \mathrm{C}$ for diazo dye adsorption on the oxide surface and irradiated by UV light for diazo dye decolourization. The mixture of $\mathrm{ZnO}$ containing, respectively, 3 and $5 \%$ cobalt oxide showed higher decolourization rate constant in comparison to $\mathrm{ZnO}$.
\end{abstract}

Keywords. Photocatalysis; diazo dye; oxide mixture; p-n junction; characterization.

\section{Introduction}

Azo dyes, aromatic compounds with one or more nitrogento-nitrogen double bonds, constitute the largest and the most different groups of synthetic dyes and have been widely used in many industries that produce huge amounts of polluted effluents, generally discharged to surface water bodies and ground water aquifers. Due to the poor exhaustion properties, the loss of the initial dye in wastewaters can attain as high as $50 \%$ for reactive dyes, leading to severe contamination in the vicinity of dyeing industries. These dyes are considered toxic and mutagenic to the living organisms in aquatic environment. In addition, the stability of their molecular structures provides them resistant to biological or even chemical treatments. $^{1-5}$

Because of the environmental problems, technologies that mineralize and degrade organic and inorganic contaminants to $\mathrm{CO}_{2}$, water and inorganic ions have been studied. ${ }^{6}$ Conventional treatments such as precipitation and separation, coagulation, active carbon elimination and others have been used for textile waste removal, but none of these methods degrades completely the contaminant. ${ }^{7}$ In recent times efforts have been devoted to the investigation of photochemical processes using n-type semiconductor oxides, such as

\footnotetext{
*Author for correspondence (keiko@uel.br)
}

$\mathrm{TiO}_{2}, \mathrm{ZnO}$ in heterogeneous system. When this semiconductor is illuminated by light rays with wavelength below $380 \mathrm{~nm}$, the photons excite valence band electrons across the band gap into the conduction band, leaving holes behind in the valence band. These holes react with water molecules or hydroxide ions in order to produce hydroxyl radical $\left(\mathrm{HO}^{\bullet}\right)$, which presents high oxidation potential $(2.8 \mathrm{~V})$ and oxidizes the majority of the organic compounds due to low selectiveness. ${ }^{8,9}$ On the other hand, the electron-hole recombination occurs and releases energy as heat, radiation or light. This phenomenon, known as photoluminescence, has been investigated in order to obtain information about the efficiency of the charge carrier processes as trapping, transfer and migration, and provides a method to understand the physical and photochemical properties of the semiconductor. ${ }^{10,11}$ Hence, the heterogeneous photocatalysis mediated by semiconductor has been widely used as an alternative for decontamination of polluted waters with organic and inorganic substances. ${ }^{12,13}$

The interaction between n- and p-type semiconductors can form the $\mathrm{p}-\mathrm{n}$ junction and facilitate the electron-hole pair formation, decreasing the band gap energy, which increases the photocatalytic efficiency. ${ }^{14}$ Taking into account that ntype semiconductor has electrons and p-type, holes, the latter tends to diffuse and occupy uniformly the network, while the n-type electrons tend to do the same. Hence, the electron diffuses to $\mathrm{p}$-side, leaving a positive charge in the n-side. 


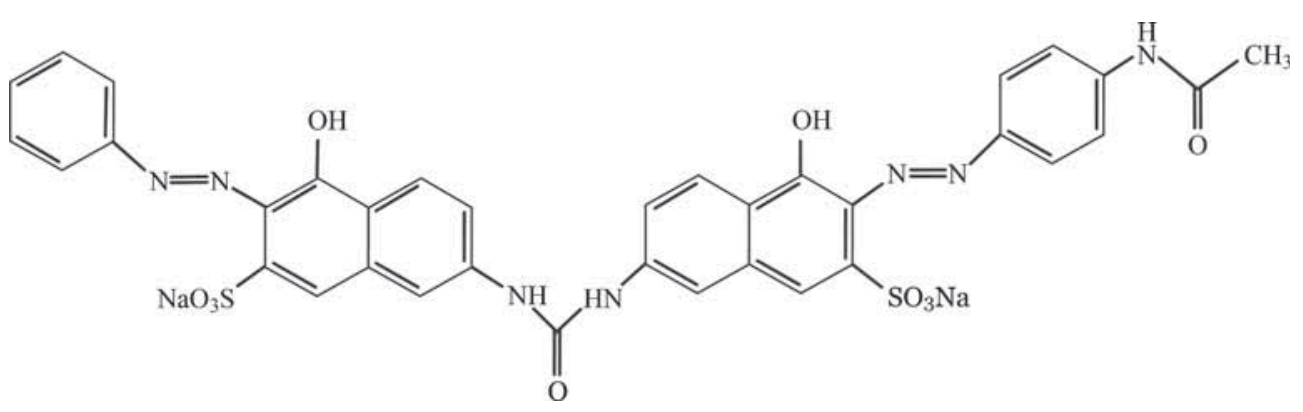

Figure 1. Schematic structure of direct red 23 diazo dye, sodium 3-[[4-(acetylamino)-phenyl] azo]-4-hydroxy-7-[[[[5-hydroxy-6-(phenylazo)-7-sulpho-2-naphthalenyl]-amino] carbonyl] amino]-2naphthalenosulphonic acid.

The p-side hole behaves similarly, leaving a negative charge in the p-side. These exchanges generate an electric field owing to the double electric layer, which is directed from $\mathrm{n}$ - to $\mathrm{p}$-side, inhibiting the holes and electrons diffusion to the former state, maintaining the separation among holes and electrons, avoiding the recombination of these by time period. ${ }^{15}$

The objective of this work was to prepare and to characterize the zinc oxide and cobalt oxide mixtures in different proportions in order to verify their photocatalytic activities through the direct red 23 diazo dye decolourization at $30^{\circ} \mathrm{C}$, whose chemical structure is shown in figure 1 .

\section{Experimental}

\subsection{Oxides preparation}

Cobalt oxide was prepared from equal volumes of 0.40 mol $1^{-1}$ hexahydrate cobalt nitrate $\left(\mathrm{Co}\left(\mathrm{NO}_{3}\right)_{2} \cdot 6 \mathrm{H}_{2} \mathrm{O}\right.$, Synth. $99 \%)$ and $0.60 \mathrm{~mol} 1^{-1}$ anhydrous oxalic acid $\left(\mathrm{H}_{2} \mathrm{C}_{2} \mathrm{O}_{4}\right.$, Belga, P.A. 99\%), both dissolved in deionized water (MilliQ) and boiled separately. In this temperature the cobalt hexahydrate nitrate was added to the oxalic acid and the heating immediately stopped. The resulting mixture was magnetically stirred (Microquímica AMA 301) until it reached the room temperature. The precipitate was filtered at vacuum, washed with distilled water several times, air dried overnight, subsequently placed in a drying oven at $100^{\circ} \mathrm{C}$ (Biopar S150SD) during $3 \mathrm{~h}$ and lastly, taken to the preheated muffle furnace (Marconi MA385) at $400^{\circ} \mathrm{C}$ for $12 \mathrm{~h}$ to obtain cobalt oxide. The prepared oxide was added to $\mathrm{ZnO}$ (Nuclear, P.A., 99\%) to formulate mixtures containing 1, 3, and $5 \%$ of cobalt oxide. The both oxides were macerated in an agate mortar during $2 \mathrm{~h}$ until the mixture becomes homogeneous. Afterward, this material was transferred to the crucible and taken to the muffle oven for calcination at $400^{\circ} \mathrm{C}$ for a period of 5 h. ${ }^{16}$

\subsection{Characterizations}

The X-ray diffraction (XRD) patterns were obtained through the Rigaku diffractometer D/MAX-2100/PC with $\mathrm{CuK}_{\alpha 1}$ $(\lambda=1.5406 \AA)$ line used as the radiation source. The applied tension was $40 \mathrm{kV}$ and the current of $30 \mathrm{~mA}$. The scanning range of $2 \mathrm{~h}$ was $10-80^{\circ}$ with regular steps of $0.05^{\circ}$ per second. Band-gap energy $\left(E_{\mathrm{g}}\right)$ was determined by diffuse reflectance (DRS) using a Shimadzu UV-2600 UV-vis spectrophotometer. Oxide particles morphology was observed by scanning electron microscopy (SEM) using Phillips FEI Quanta 200. The composition and distribution of oxides surface were determined by $\mathrm{X}$-ray energy-dispersive spectroscopy (EDX) using the same microscope of SEM. The percentage of elements present in the oxides was determined by X-ray fluorescence spectroscopy (XRF) through the Shimadzu EDX-720HS Ray-ny spectrophotometer.

\subsection{Heterogeneous photocatalysis}

The heterogeneous photocatalysis of the direct red 23 diazo dye (DR23) (Chemical) was performed inside a wooden box $\left(50 \times 50 \times 50 \mathrm{~cm}^{3}\right)$, covered internally with aluminium foil and closed in the frontal part with a black curtain. A suspension formed by $150 \mathrm{ml}$ of $7.5 \times 10^{-3} \mathrm{~mol}^{-1}$ DR23 and $3.0 \mathrm{~g}^{-1}$ semiconductor was placed in a borosilicate double wall glass reactor $(200 \mathrm{ml}$, homemade), stirred magnetically at $600 \mathrm{rpm}$ (Fisatom 752) in the dark during $60 \mathrm{~min}$, whose temperature of $30.0 \pm 0.1^{\circ} \mathrm{C}$ was maintained by water circulation (Microquímica MQBT99-20). Subsequently, the irradiation was started using an $\mathrm{Hg}$ vapour lamp without bulb (Phillips HPL-N 125W), positioned horizontally and centralized at the top of the box at a distance of $10 \mathrm{~cm}$ from the reactor. One millilitre aliquots were collected as a function of irradiation time, filtered (Millipore, $0.22 \mu \mathrm{m}$ ), and the UV-vis spectra (Hitachi U-3000) were registered from 200 to $700 \mathrm{~nm}$, monitoring the DR23 maximum absorbance at $503 \mathrm{~nm}\left(\varepsilon=2.54 \times 10^{4} \mathrm{~cm} \mathrm{~mol}^{-1} 1, r=0.999\right) .{ }^{17}$ The decolourization rate constant, $k_{\mathrm{obs}}$, was determined under pseudo-zero-order kinetic condition, as a function of irradiation time $t$, in triplicate, wherein the absorbance in $t$ time and zero are represented, respectively, by $A_{t}$, and $A_{0}$

$$
A_{t}=-k_{\mathrm{obs}} t+A_{0} .
$$




\section{Results and discussion}

\subsection{XRD investigation}

The X-ray diffraction patterns of the pure zinc oxide $(\mathrm{ZnO})$, the mixture containing 1 (OMCo1), $3(\mathrm{OMCo} 3)$, and 5 $(\mathrm{OMCo} 5)$ wt $\%$ of cobalt oxide $\left(\mathrm{Co}_{3} \mathrm{O}_{4}\right)$, and the pure $\mathrm{Co}_{3} \mathrm{O}_{4}$ can be seen in figure 2 .

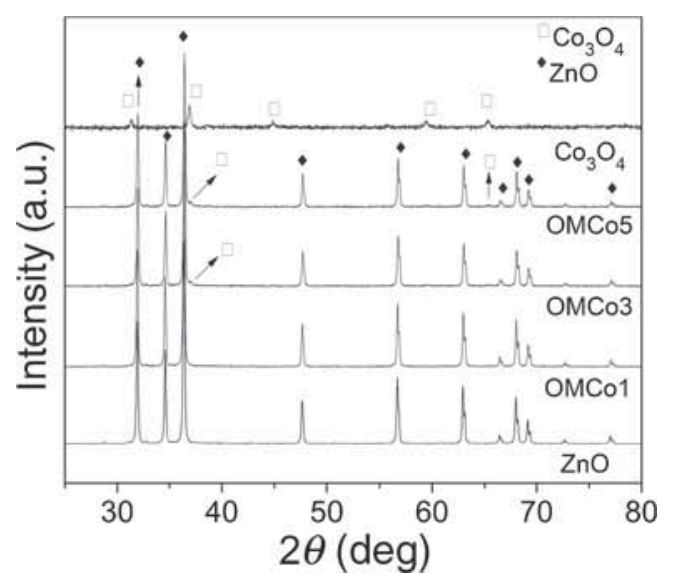

Figure 2. XRD patterns of pure $\mathrm{ZnO}$, mixture containing 1, 3, and $5 \mathrm{wt} \%$ of $\mathrm{Co}_{3} \mathrm{O}_{4}$ and pure $\mathrm{Co}_{3} \mathrm{O}_{4}$.
The XRD patterns of cobalt oxide display the diffracted peaks at about $2 \theta=31.3,36.9,44.9,59.4$ and $65.3^{\circ}$. These peaks are associated with the crystallographic planes (220), (311), (400), (511) and (440) of the $\mathrm{Co}_{3} \mathrm{O}_{4}$ cubic structure with spatial group $\mathrm{Fd}-3 \mathrm{~m}$ (227) and lattice parameter $a=$ $8.084 \AA$, obtained by comparison with the crystallographic pattern from the file PDF \#42-1467 of the PCPDFWIN software (version 2.4, JCODS-ICDD). This result presents good agreement with the previously published papers about cobalt oxide synthesis. ${ }^{18,19}$ Through the XRD patterns of pure $\mathrm{ZnO}$, all the diffracted peaks can be indexed as hexagonal structure with spatial group P6 ${ }_{3} \mathrm{mc}$ (186) and lattice parameters $a=$ $3.249 \AA$ and $c=5.206 \AA$ (PDF \# 65-3411). The same profile was observed for $\mathrm{OMCo} 1, \mathrm{OMCo} 3$, and $\mathrm{OMCo} 5$ in the XRD patterns, where in the $\mathrm{OMCo} 3$ and $\mathrm{OMCo} 5$ samples the diffraction peaks of cubic $\mathrm{Co}_{3} \mathrm{O}_{4}$ were observed. The characteristic peaks of $\mathrm{ZnO}$ (considering the three highest intensity peaks) decrease when the $\mathrm{Co}_{3} \mathrm{O}_{4}$ percentage was increased; this implies that cobalt has contributed to a more amorphous crystal lattice of $\mathrm{ZnO}$. Is also observed that with increase of cobalt oxide (OMCo1, OMCo3 and OMCo5 samples) the peak position of the $\mathrm{ZnO}$ hexagonal structure shifts to higher angles compared with pure $\mathrm{ZnO}$. This shift in the $2 \theta$ angle can be associated with the difference between ionic radius of $\mathrm{Zn}^{2+}(0.74 \AA)$ and $\mathrm{Co}^{3+}(0.61 \AA)$, where the $\mathrm{Co}^{3+}$ leads to the distortion on $\mathrm{ZnO}$ lattice. ${ }^{20}$ These XRD results about pure
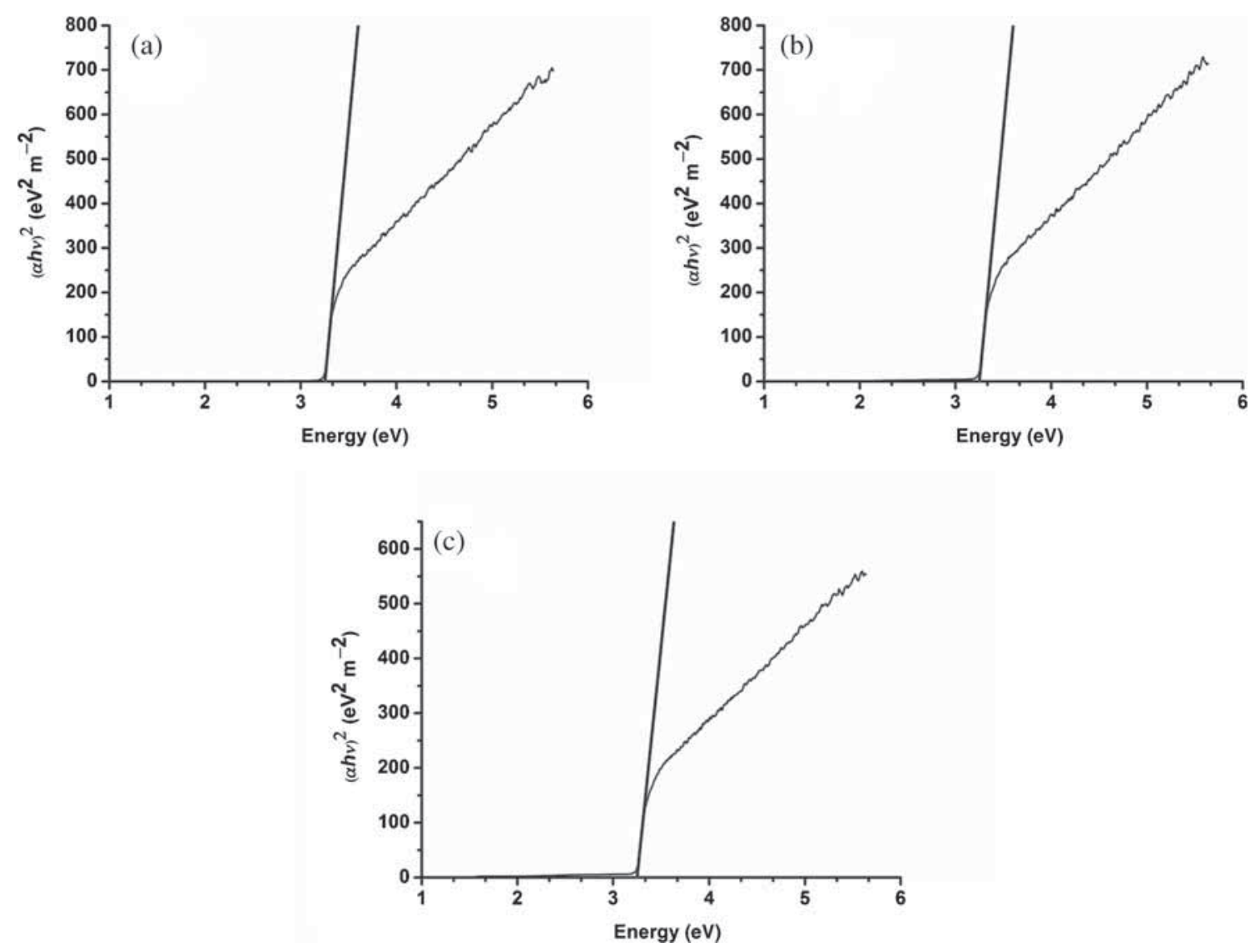

Figure 3. Tauc diagrams showing fits to obtain band gap energies of (a) OMCo1, (b) OMCo3 and (c) OMCo5. 
$\mathrm{ZnO}$ and mixed $\mathrm{ZnO}$ with $\mathrm{Co}_{3} \mathrm{O}_{4}$ are in good agreement with some previously published papers concerning to the relative intensity and the peaks position. ${ }^{21-23}$

\subsection{Band gap energy determination}

The band-gap energy $\left(E_{\mathrm{g}}\right)$ of the oxide mixtures was obtained from the diffuse reflectance spectra as a function of wavelength, $\lambda$ through the Tauc energy diagram (2), where $\alpha$ represents the absorption coefficient, $h v$ the photon energy and $C$ a constant.

$$
(\alpha h v)^{2}=C\left(h v-E_{\mathrm{g}}\right) .
$$

Figure 3 displays the Tauc diagrams of the oxide mixtures, where $E_{\mathrm{g}}$ was determined from the intersection in abscissa, corresponding to the absorbed radiation. From figure $3 \mathrm{a}$ to $\mathrm{c}$, the band gap energies of $3.24,3.25$ and $3.25 \mathrm{eV}$ were determined for OMCo1, OMCo3 and OMCo5, respectively. These results indicated that, all the oxide mixtures presented smaller band gap energy compared to pure $\mathrm{ZnO}(3.26 \mathrm{eV})$, whose energy was determined (diagram not shown).

\subsection{Scanning electron microscopy}

The SEM images of the cobalt oxide and oxide mixtures, magnified by 8000 times, are displayed in figure 4 . The rod-shaped particles, displayed in figure $4 \mathrm{a}$, corresponds to $\mathrm{Co}_{3} \mathrm{O}_{4}$ according to Salavati-Niasari et $a l^{24}$ and $\mathrm{Xu}$ et $a l^{25}$ in agreement with the XRD results. The images of OMCo1, $\mathrm{OMCo} 3$ and $\mathrm{OMCo} 5$, figure $4 \mathrm{~b}$ to $\mathrm{d}$ exhibit the homogeneous distribution of $\mathrm{Co}_{3} \mathrm{O}_{4}$ crystals over the oxide mixture surface. The presence of $\mathrm{Co}_{3} \mathrm{O}_{4}$ crystals confirms that, since the oxide mixture was prepared by maceration, the physical

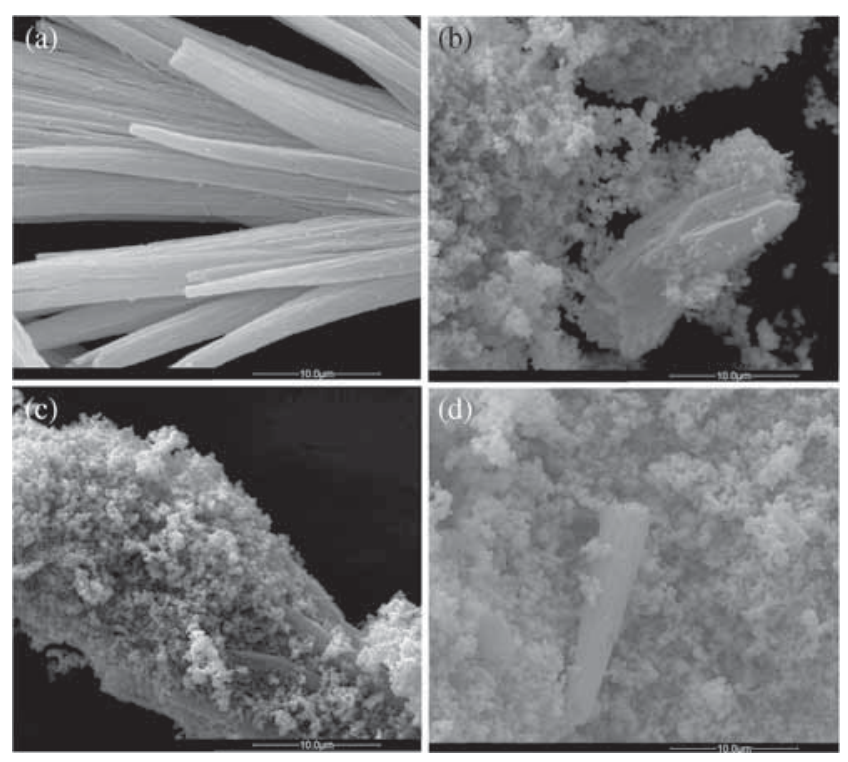

Figure 4. SEM images magnified by $\times 8000$ of (a) $\mathrm{Co}_{3} \mathrm{O}_{4}$, (b) $\mathrm{OMCo} 1$, (c) $\mathrm{OMCo} 3$ and (d) OMCo5. interaction and therefore, superficially, takes place on the $\mathrm{ZnO}$ surface.

The chemical elements were determined in the prepared cobalt oxide by EDX (images not shown). Oxygen and cobalt were distributed uniformly in $\mathrm{Co}_{3} \mathrm{O}_{4}$ crystals, while more concentrated regions of cobalt were observed in the oxide mixture. Furthermore, the zinc was uniformly distributed throughout oxide mixture, suggesting that $\mathrm{ZnO} / \mathrm{Co}_{3} \mathrm{O}_{4}$ interaction was physical due to preparation method.

\section{$3.4 \quad X$-ray fluorescence spectroscopy}

Figure 5 displays the X-ray fluorescence spectra of the cobalt oxide (figure 5a) and zinc oxide containing, respectively, 1 , 3 and 5\% of cobalt oxide (figure 5b-d). The percentages of these components in the prepared oxides were obtained from these spectra. Cobalt oxide (figure 5a) presented $99.938 \%$ of cobalt with fluorescence at 6.94 and $7.66 \mathrm{keV}$, and the impurity $(0.062 \%)$ displayed fluorescence at $5.47 \mathrm{keV}$. Unexpectedly, the prepared oxide mixtures presented 1.437, 3.893 and $5.526 \%$ of cobalt, which presented fluorescence at 6.93 and $7.66 \mathrm{keV}$. So, the zinc percentage was respectively 98.563 , 96.107 and $94.474 \%$, where the fluorescence took place at 8.64 and $9.58 \mathrm{keV}$. These spectra suggest that the cobalt peak intensity rises with the cobalt oxide quantity in oxide mixture.

\subsection{Photocatalytic activity studies}

The direct red 23 diazo dye (DR23) photocatalysis, mediated by oxide mixtures at $30^{\circ} \mathrm{C}$, was performed under pseudo-order conditions, using a large excess of semiconductor $\left(3.0 \mathrm{~g}^{-1}\right)$ in comparison to the diazo dye $\left(7.5 \times 10^{-5}\right.$ mol $1^{-1}$ ). When the first-order kinetic law was applied, this behaviour followed about 1-h irradiation ( $r \geq 0.976$ ), after this, it took place a relatively high deviation in the points $(r \leq 0.950)$. Conversely, the same absorbance values, applied to the zero-order kinetics, resulted in a linear absorbance decrease $(r \geq 0.989)$. This means that the reaction rate is independent of the diazo dye concentration, suggesting that the semiconductor surface adsorbs all the substrate molecules and any substrate addition will not affect the surface reaction rate, implying that the reaction follows the Langmuir adsorption mechanism ${ }^{26,27}$ as

$$
r=k\left(\frac{K C}{1+K C}\right) \text {, }
$$

where $r$ is the surface reaction rate, $k$ the rate constant, $K$ the adsorption constant and $C$ the substrate concentration. As mentioned previously, the decolourization of the direct red 23 diazo dye showed a kinetic behaviour of zero order. This means that, the adsorption constant is considerably larger than the concentration in (3), demonstrating a large amount of active sites on the semiconductor surface.

The diazo dye decolourization rate constants as well as the decolourization percentage are displayed in table 1 . 

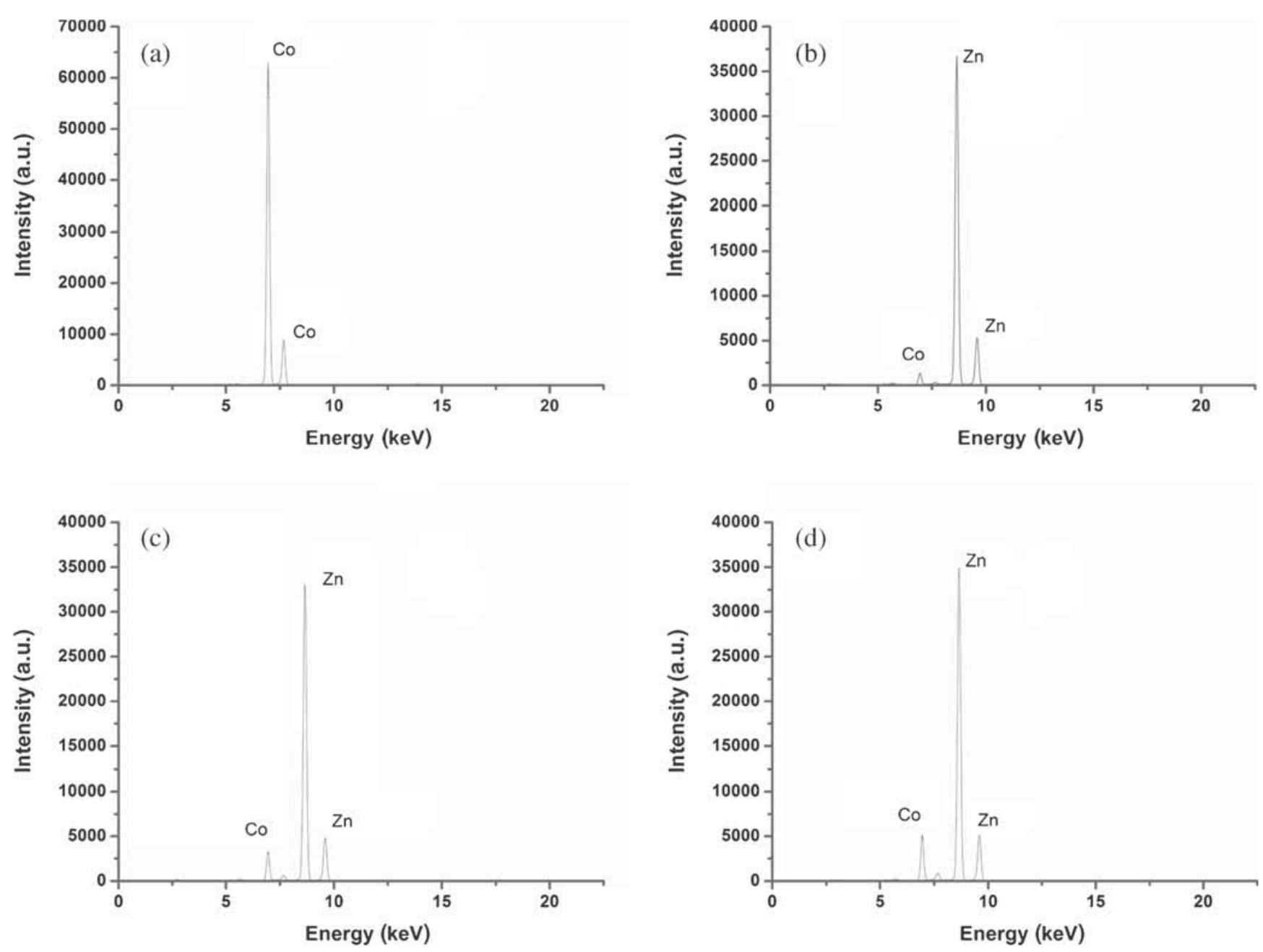

Figure 5. XRF spectra of (a) $\mathrm{Co}_{3} \mathrm{O}_{4}$, (b) OMCo1, (c) $\mathrm{OMCo} 3$ and (d) OMCo5.

Table 1. Decolourization rate constants, $k_{\mathrm{obs}}$, of DR23 $\left(7.5 \times 10^{-5} \mathrm{~mol} \mathrm{1^{-1 }}\right)$ as a function of $\mathrm{Zn} / \mathrm{Co}$ proportions in the oxide mixture $\left(3.0 \mathrm{~g}^{-1}\right)$ at $30^{\circ} \mathrm{C}$.

\begin{tabular}{rccccc}
\hline$\% \mathrm{Zn}$ & $\% \mathrm{Co}$ & $E_{\mathrm{g}} / \mathrm{eV}$ & $k_{\mathrm{obs}} / 10^{-3} \mathrm{~mol} \mathrm{l}^{-1} \mathrm{~min}^{-1}$ & $r$ & Decolourization $/ \%$ \\
\hline 100 & 0 & 3.26 & $4.710 \pm 0.143$ & 0.9909 & $90.05 \pm 4.59$ \\
99 & 1 & 3.24 & $4.320 \pm 0.085$ & 0.9892 & $92.07 \pm 1.68$ \\
97 & 3 & 3.25 & $5.560 \pm 0.143$ & 0.9889 & $88.95 \pm 7.48$ \\
95 & 5 & 3.25 & $5.370 \pm 0.240$ & 0.9917 & $86.76 \pm 9.31$ \\
\hline
\end{tabular}

From table 1 the decolourization rate constant of DR23 in the presence of $\mathrm{ZnO}$ was $4.710 \times 10^{-3} \mathrm{~mol}^{-1} \mathrm{~min}^{-1}$ at $30^{\circ} \mathrm{C}$. This means that $\mathrm{OMCo} 3$ and $\mathrm{OMCo} 5$ presented higher rate constants equivalent to $5.560 \times 10^{-3}$ and $5.370 \times 10^{-3}$ mol $1^{-1} \mathrm{~min}^{-1}$, that is, 18 and $13 \%$ higher than $\mathrm{ZnO}$. On the other hand, $k_{\mathrm{obs}}$ for OMCo1 resulted in $4.320 \times 10^{-3} \mathrm{~mol} \mathrm{l}^{-1}$ $\mathrm{s}^{-1}$ or $7 \%$ lower than $\mathrm{ZnO}$, regardless of the band gap energy of $3.24 \mathrm{eV}$.

The lowest photocatalytic activity for OMCo1 was unexpected, because, in principle, the rate constant in the presence of p-type semiconductor should have enhanced. This may be ascribed to the further number of holes in the system that caused a higher electron-hole recombination. With the respect to the higher rate constants attained by OMCo3 and OMCo5, it may be justified as the large number of trapping carrier sites that could lengthen the carrier lifetime and thus the photocatalytic activity. Furthermore, a $\mathrm{p}-\mathrm{n}$ junction may be formed with adequate amount of $\mathrm{p}$-type semiconductor in order to generate the electric field between semiconductors, causing a charge separation. Apparently, the OMCo5 rate constant is lower than OMCo3, however the band-gap energies $(3.25 \mathrm{eV})$ are the same for two oxide mixtures. Moreover, these values can be considered practically equal owing to the rate constants deviation, thus 
the photocatalytic activities are very similar. The OMCo1 kinetic behaviour is opposite in comparison to $\mathrm{OMCo} 3$ and $\mathrm{OMCo} 5$, that is, the rate constant decrease for OMCo1 and increase for other two oxide mixtures. Therefore, there is an optimum p-type semiconductor concentration range, where occurs the $\mathrm{p}-\mathrm{n}$ junction in order to improve the photocatalytic activity. ${ }^{28,29}$

All the oxides provided an average dye decolourization of $90 \%$, as displayed in table 1 . Comparing $k_{\text {obs }}$ values with diazo dye decolourization percentages that $\mathrm{OMCo} 1$ presented the highest percentage, however the irradiation time was of $180 \mathrm{~min}$. In this case, the suspension containing OMCo1 was irradiated more than $60 \mathrm{~min}$ with respect to other oxides to reach the absorbance lower than 0.100 .

\section{Conclusions}

This work showed a simple method to prepare a zinc and cobalt (II, III) oxide phase mixture with band gap energies of $\mathrm{OMCo} 1, \mathrm{OMCo} 3$ and $\mathrm{OMCo} 5$ were respectively equivalent to $3.24,3.25$ and $3.25 \mathrm{eV}$, lower than the pure $\mathrm{ZnO}, 3.26 \mathrm{eV}$. The photocatalytic activity increased with the cobalt oxide concentration. $\mathrm{OMCo} 3$ and $\mathrm{OMCo} 5$ presented better photocatalytic activities with zero order rate constants, respectively, equal to $5.56 \times 10^{-3}$ and $5.37 \times 10^{-3} \mathrm{~mol} \mathrm{l}^{-1} \mathrm{~min}^{-1}$ with respect to $\mathrm{ZnO}$ with $4.71 \times 10^{-3} \mathrm{~mol}^{-1} \mathrm{~min}^{-1}$.

\section{References}

1. Daneshvar N, Salari D and Khataee A R 2004 J. Photochem. Photobiol. A: Chem. 162317

2. Hayat K, Gondal M A, Khaled M M, Yamani Z H and Ahmed S 2011 J. Hazard. Mater. 1861226

3. Kunz A, Peralta-Zamora P, Dúran N and De Moraes S G 2002 Quím. Nova 2578

4. Pandey A, Singh P and Iyengar L 2007 Int. Biodeterioration Biodegrad. 5973

5. Zollinger H 1991 Color chemistry: syntheses, properties and applications of organic dyes and pigments (Weinheim: $\mathrm{VCH}$ ) 2nd ed., p 109

6. Rey A, Carbajo J, Adán C, Faraldos M, Bahamonde A, Casas J A and Rodriguez J J 2011 Chem. Eng. J. 174134

7. Tanaka K, Padermpole K and Hisanaga T 2000 Water Res. 34 327
8. Augugliaro V, Baiocchi C, Prevot A B, García-López E, Loddo V, Malato S, Marcí G, Palmisano L, Pazzi M and Pramauro E 2002 Chemosphere 491223

9. Legrini O, Oliveros E and Braun A M 1993 Chem. Rev. 93 671

10. Lai Y, Meng M, Yu Y, Wang X and Ding T 2011 Appl.Catal. B: Environ. B 105335

11. Liqiang J, Yichun Q, Baiqi W, Shudan L, Baojiang J, Libin Y, Wei F, Honggang F and Jiazhong S 2006 Sol. Energy Mater. Sol. Cells 901773

12. Rasoulifard M, Fazli M and Eskandarian M 2014 J. Ind. Eng. Chem. 203695

13. Rubio-Clemente A, Torres-Palma R A and Peñuela G 2014 Sci. Total Environ. 478201

14. Azmi B Z, Liaw H S, Hashim M, Moksin M M, Yunus W M M and Yusoff W M D W 2002 J. Fiz. Malaysia 23110

15. Kittel C 1996 Introduction to solid state physics (New York: John Wiley) 7th ed

16. Muruganandham M, Chen I S and Wu J J 2009 J. Hazard. Mater. 172700

17. Lucilha A C, Bonancêa C E, Barreto W J and Takashima K 2010 Spectrochim. Acta Part A: Mol. Biomol. Spectros. 75 389

18. Gu Y, Jian F and Wang X 2008 Thin Solid Films 517652

19. Nassar M Y 2013 Mater. Lett. 94112

20. Liu L, Li S, Zhuang J, Wang L, Zhang J, Li H, Liu Z, Han Y, Jiang X and Zhang P 2011 Sens. Actuators B: Chem. 155782

21. Anandan S, Vinu A, Mori T, Gokulakrishnan N, Srinivasu P, Murugesan V and Ariga K 2007 Catal. Commun. 81377

22. Djenadic R, Akgül G, Attenkofer K and Winterer M 2010 J. Phys. Chem. C 1149207

23. Kong J Z, Li A D, Zhai H F, Gong Y P, Li H and Wu D 2009 J. Solid State Chem. 1822061

24. Salavati-Niasari M, Mir N and Davar F 2009 J. Phys. Chem. Solids 70847

25. Xu J, Cai J, Wang J, Zhang L, Fan Y, Zhang N, Zhou H, Che D, Zhong Y, Fan H, Shao H, Zhang J and Cao C 2012 Electrochem. Commun. 25119

26. Hasnat M A, Uddin M M, Samed A J F, Alam S S and Hossain S 2007 J. Hazard. Mater. 147471

27. Murzin D Y 2008 Catal. Commun. 91815

28. Long M, Cai W, Cai J, Zhou B, Chai X and Wu Y 2006 J. Phys. Chem. B 11020211

29. Shifu C, Sujuan Z, Wei L and Wei Z 2008 J. Hazard. Mater. 155320 